\title{
THE EVOLUTION OF THE CONCEPTS OF INFANT FEEDING*
}

\author{
BY \\ ALTON GOLDBLOOM \\ Emeritus Professor of Paediatrics, McGill University, Montreal
}

(RECEIVED FOR PUBLICATION MAY 3, 1954)

In those suspended moments of late night, midway between sleeping and waking, my thoughts drift dreamily to the subject and the matter of the Windermere Lecture. The thoughts come readily and they are masterly, indeed they border on genius, the phrases are limpid and poetic, their cadences have a majestic grandeur, a blending of sublime prose and poetry so subtle, smooth and lilting and so profound. Just what is appropriate for an honour so great. I must get up at once and write it all down while it is still fresh; such inspiration comes but rarely. Yet, I have it all quite clearly point by point, phrase by phrase, the apt similes, the poetic imageries, the noble prose, why not sleep and first thing in the morning . . . But alas, first thing in the morning it has all flown. Vague and formless thoughts without limpid phrase or prose or poetry or indeed substance are all that remain. I return from the facile fancies of my dreams-which would have made a superb lecture-to the mundane limitations of my waking hours and attempt to construct a lecture worthy of this occasion.

Paediatrics in the first two decades of this century in North America concentrated its greatest attention on infant feeding. A few other principles were emphasized such as the importance of examining the eardrums and the urine of the sick infant, a few eponymic diseases and symptoms were described but the gastro-intestinal tract in health and in disease received the greatest emphasis and there arose schools and methods of infant feeding. Like metaphysics, it was the search in an absolutely black room for an absolutely black hat that wasn't there! There were several black hats but not in the black room. They were before us all the time and it needed only the clearing of the mists before our eyes that they be seen.

In the first edition of Holt's Diseases of Children published in 1888 is a beautiful illustration. It is two pages wide and is unfolded in order to be seen. It represents the stomach capacities of infants at different ages. The illustration represents a number of post-mortem, rigor mortis stomachs, apparently filled with fluid, the volume held in these dead stomachs purporting to represent the capacities of live infant stomachs at various ages. From these momentous studies was evolved a rule of the quantity that may be fed an infant at any given age; it was 'age in months plus one'. Thus a 2-month-old infant may be fed no more than $3 \mathrm{oz}$. and so on. Some inconsiderate infants did not know this rule and their vocal demands for more food was called colic, and this in turn gave rise to more and diversified ideas on the causes of colic, its prevention and treatment, but never to the idea that the hungry baby might appreciate being made an exception to the hard and fast rule of age in months plus one. The breast-fed infant went merrily on feeding, sleeping and gaining, until one day some inspired pediatrician invented test weighing. This brought to light a number of infants who had no regard for the rule whatsoever; some who at 5 or 6 weeks of age were found to consume as much as 5 or $6 \mathrm{oz}$. at a time and this after only a few minutes at the breast, despite the dictum of the sages that the infant must nurse at the breast for 20 minutes, shorter periods, of course, leading to gastric distension and to colic. However, a new fact must give birth to a new theory. There developed the concept of the anatomic capacity of the stomach-age in months plus one-and the physiological capacity of the stomach, amount undetermined. Armed with this new theory one could now proceed to the obvious, namely to permit the infant to determine his quantity of food by the simple device of permitting him to follow his own desires.

The disastrous results of artificial infant feeding -or hand feeding as it is called in England-was of course one reason for the emphasis then laid on breast feeding and on wet nursing. There was the

* The Windermere Lecture given before the British Paediatric Association at Windermere on April 29, 1954. 
noble and almost missionary work of Sedgwick which came almost to naught with the later improvement of ideas and methods of artificial infant feeding; but in this era of confusion Sedgwick's work was life saving. The era was not without its humour, not the least of which was Osler's impish joke at a dinner in New York in the year 1900 celebrating the seventieth birthday of Abraham Jacobi. Osler was a member of the American Pediatric Society and its third president. In his speech at this dinner in the midst of his complimentary remarks about Jacobi, as Cushing remarks, his alter ego, E. Y. Davis, got the better of him and in all seriousness he spoke as follows:

'There is no single question before the nation today of greater importance than how to return to natural methods in the nurture of infants. The neglect is an old story in Anglo-Saxondom. St. Augustine, so Bede tells us, wrote to Pope Gregory complaining that the question of infant feeding was worrying him not a little! I understand that a systematic effort is to be made to supply every child born in this land its rightful sustenance for one year at least. Under the auspices of the Pediatric Society and the Women's Christian Temperance Union, a Women's Infant's Suckling Union is to be established, which will strive to make it a criminal offence against the State to bottle feed any baby, and which will provide in large and well equipped sucklingries ample sustenance when a mother from any cause is unable to do her duty. Dr. Rotch tells me that the action on the part of the Pediatric Society has been influenced by an exhaustive collective investigation which has been made on the future of bottle-fed babies, in which it is clearly shown that intellectual obliquity, moral perverseness and special crankiness of all kinds result directly from the early warp given by the gross and unworthy deception to which it is subjected-a deception which extends through many months of the most plastic period of its life. According to these researches you can tell a bottle-fed man at a glance, or rather at a touch. Feel the tip of his nose. In all sucklings the physical effects of breast pressure on the nose are not alone evidenced in the manner set forth so graphically by $\mathrm{Mr}$. Shandy, but in addition the two cartilages are kept separate and do not join; whereas in bottle-fed babies in whom there is no pressure on the tip of the nose the cartilages rapidly unite, and in the adult present to the finger a single sharp outline entirely different from the split bifid condition in the breast-fed child. The collective investigations demonstrate that all silver democrats, many populists, and the cranks of all descriptions have been bottle-fed, and show the characteristic nose-tip. Utopian as this scheme may appear, and directly suggested, of course, by Plato, who can question the enormous benefit which would follow the substitution of sucklingries for WalkerGordon laboratories and other devices!. . .'

The appalling mortality of infants during the first year of life together with the vague, controversial and often ineffective methods of infant feeding, lent, of course, an increased importance to human milk as a way out of the difficulties. This led to the development of methods of collecting and storing human milk, which at best was in such short supply that it was used very sparingly almost like a medicine. An ounce might be added to the whole day's cow's milk mixture, and this only in the desperate cases.

In Boston and in New York during my days as house officer there were district nurses whose business it was to follow up those mothers who left the lying-in hospitals still nursing their babies and to offer to buy their excess of milk. The mothers were instructed in the method of stripping their breasts and were paid about six cents an ounce for the product. The 'milkmaids' would leave the hospital in the morning with empty sterilized feeding bottles and would return towards evening laden with the day's milking. In order to enhance their earnings, the mothers were not above adulterating their milk. They either added water or they added cow's milk. It was my duty to attempt to detect the frauds by testing the specific gravity and by making a fat analysis. With these and other tests we could usually detect the impostors and buy no more of thieir inferior product.

Wet nurses were a quarrelsome and in other ways a troublesome lot. They were housed in the hospital and their infants boarded in the same institution. Most of these were homeless women of low intelligence and morals. The milk obtained under supervision was naturally of good quality but the quantity produced hardly warranted the trouble and expense of keeping them. They were all imbued with feelings of indispensability which made them insufferable. The practice was short lived.

The textbooks of the day, in dealing with wet nurses emphasized the importance of the character of the wet nurse-she must be good natured and calm. I have often wondered if this was not a relic of the days when it was believed that the infant sucked character from his nurse. 'Thy valiantness was mine, thou sucks't it from me' or 'From my dugs he drew not such conceits'-I think these phrases, in the beliefs of the times, had more than a symbolic meaning.

Cardinal Riccardo Petroni, of Siena, who died in 1313, was disgusted with the vulgar Italian tongue and the quality of ecclesiastical Latin of his day and left elaborate provisions in his will for the importing of Latin-speaking wet-nurses and for the founding of the Petronian College of Latin-speaking Wetnurses. The idea was not carried out until 1719. Their infants were to hear nothing but Latin and only before going out into the world were they to 
be taught sufficient Italian to avoid their being taken for illiterate ignoramuses. Needless to say, the project did not long survive-but wet nursing survived until the dawn of the present era of better understanding of the nutritional needs of the infant and of how by simple means to provide them.

There was then, as now, never enough breast milk to go around and the problem of artificial feeding as it was called, was ever present. To quote L. Emmett Holt Junior, from his preface to a little book on Modern Trends in Infant Nutrition and Feeding by Jonathan Lanman:

'To the student of infant feeding whose training goes back to the early part of the present century, the subsequent decades of American pediatric history have brought the painful necessity of unlearning many of the gospel truths instilled by his preceptor. Infant feeding was then not only a science; it was a fine art. The vitamins were still unborn, and amino-acids formed no part of the clinician's vocabulary, but the task of juggling the percentages of protein, fat and carbohydrate to suit the child's digestion was sufficiently engrossing and complex. We knew the percentages of these foodstuffs that could be tolerated and what would happen if this tolerance were exceeded. We worried about curds, about the harmful effects of volatile fatty acids and the potential laxative effects of various carbohydrates. We knew the cause of digestive disorders; they were, of course, due to the foodtoo much of this or that had been given. We knew in general what to do for these disorders, but it was reserved for the skilled pediatrician to manage the "difficult feeding case"- to use the food materials of that day and with a master's touch to avoid the Scylla of indigestion and the Charybdis of inanition. When he failed there was always breast milk to turn to as a last resort; the wet nurse was still in her hey-day, and the breast milk dairy prospered.'

The search for a satisfactory substitute for human milk is probably as old as history. Itself a fruitful subject for research and amusement but far too long a story for this short hour. Paps, milk from various animals, direct nursing from the animal-as with Romulus and Remus-dilution, addition of honey, all these have had some vogue. By the time Oliver Wendell Holmes wrote the story of Iris in his Professor at the Breakfast Table it was already the custom to dilute cow's milk and add sugar.

Iris was the child of a poor school teacher. The mother died at Iris' birth. This is how Holmes puts it:

'The poor lady, seated with her companion at the chess board of matrimony, had first pushed forward her one little white pawn upon an empty square, when the black knight, that cares nothing for castles or kings or queens, swooped down upon her and swept her from the larger board of life.'

So poor Iris was left without a mother to feed her. The boys of the school presented the poor tutor with a silver goblet. It was apparently a feeding boat for, as Holmes puts it, 'The handle on its side showed what use the boys had meant it for, and a kind letter in it, written with the best of feeling, in the worst of Latin, pointed directly to its destination.' Then he goes on, 'Out of this silver vessel, after a long, desperate strangling cry, which marked her great first lesson in the realities of life' (remember Lear'when we are born we cry that we are come to this great stage of fools'), 'the child took the blue milk, such as poor tutors and their children get, tempered with water, and sweetened a little, so as to bring it nearer the standard established by the touching indulgence and partiality of nature-who has mingled an extra allowance of sugar in the blameless food of the child at its mother's breast, as compared with that of its infant brothers and sisters of the bovine race.'

It was probably Bidert in 1905 who started some of the trends in infant feeding at the turn of the century. His studies in the chemical composition of human milk and the inevitable comparisons with that of cow's milk led to the simple conclusion that all that was required was to so alter cow's milk by dilution, addition of cream, addition of lactose, so as to make it as nearly as possible similar to human milk. Thus arose the cult of similarity. Followed to its logical conclusion it led to ridiculous attempts to simulate human milk-ridiculous, though often ingenious. Top milk mixtures, whey and cream mixtures, attempts to so regulate the content of lactalbumin and casein and salts so as to be 'exactly' like human milk. The observation that the fat droplet in cow's milk was much larger than in human milk led to the use of homogenized milk in which the fat droplets were smaller. This did not prevent the professor from administering a teaspoonful of olive oil at a time-unhomogenized-if it was indicated-of all things-for constipation! or of three teaspoonfuls of pure cod liver oil, not even emulsified when the word vitamine, spelled with an ' $e$ ', came into the language - these were medicines and did not count. It is interesting in connexion with cod liver oil to review the opinions of the giants who trod the earth in those days with reference to the efficacy of this medicine. Cod liver oil was a folk remedy for rheumatism in the eighteenth century. From rheumatism it extended to gout and from gout eventually to rickets. Still taught that the increased amount of fat increased the absorption of calcium and felt that any oil would do as well. His mixture of vegetable oils, however, contained pilchard oil and this mixture, he held, though not as palatable, was equally effective. Pilchard oil, of course, is a rich source of the 
antirachitic vitamin; but Still did not know this. The Germans, Czerny and Finkelstein, while they did use cod liver oil did not trust it without a little phosphorus, while Holt held to the idea that the fat itself was important, and during the First World War dispensed cotton seed oil to which was added one drop of oleum phosphoratum to every six ounces. He assured us that this was just as good!

Coming back to the cult of similarity, it was Gerstenberger who laboured long and diligently to produce a milk, or rather a food, that was in all possible respects similar to human milk. Similar in the content of volatile fatty acids, in the iodine number of the fat, in its congealing and melting points; similar, too, in the quantity and distribution of its mineral salts. He called this mixture 'synthetic milk adapted' and most of it had never seen a cow! S.M.A., as it is known in America, is still widely and I may say, successfully used even though the necessity of going through such chemical acrobatics has long since passed. Gerstenberger's mixture of fats contained tallow oil, cocoanut oil, cocoa butter, cod liver oil and tallow, this in order to show that replacing the butter fat mixture with a fat with the low volume fatty acid content of breast milk 'would change the dyspeptic character of the stools'.

This preoccupation with excreta by paediatricians from the turn of the century to the early twenties forms one of the most amusing chapters in the history of infant feeding. It was the coprophilic era, or the era of divination by stool. Just as in the Middle Ages diagnoses were made by inspection of the urine ('carry his water to the wise woman'), so in this era was far more attention paid to the stool than to the infant. Many a surviving American paediatrician of that era remembers the fetish that was made of the stools in those days. A young and progressive paediatrician travelling abroad would often bring home with him a complete set of moulages depicting in realistic-dare I say lifelikeform every variety of stool in every conceivable, real or imaginary, digestive derangement. Students were taught from these moulages and they were examined on them. The professor himself was, as you may imagine, the expert. A familiar scene in the days of the old Boston Floating Hospital is typical of the practices of the day. It was the ward nurse's duty to keep on hand a specimen of each child's stool. In time for ward rounds, she had these specimens neatly done up in brown paper, with the infant's name in the upper right hand corner. These were placed in a basin in alphabetical order and it was the duty of the junior interne to hold this basin in his arms, at a safe distance from the professor and his assistants and visitors, and to come forward with the specimen whenever the bed of a given infant was approached. The professor carried a handful of wooden spatulas in his breast pocket, but I do not remember him ever using it for examining an infant's throat, it was used to smear the specimen of stool, to note its consistency, to search for curds-soap and beanwith never a look at the infant, but only from this meticulous examination on which he would expatiate lengthily and eruditely, he would finally offer the suggestion for the next day's food. The order would be either increase or decrease the fat, the sugar or the protein by, usually, one quarter of $1 \%$. No regard, mark you, for the variations in the content of these substances from day to day in commercial milk, but a change from a mean figure chosen from someone's text. All this from the mere inspection of a stool sample. In his later years, L. Emmett Holt Sr., began to see the futility and the senselessness of this coprology. I remember when I was his house officer he was examining a severely marantic infant whose progress had been consistently downhill despite his best efforts. A junior interne came forward to show him what a good stool the infant had just passed. Holt's comment was, 'Well, at least he'll die with good stools'. It is much like the modern cynicism about the patient in an oxygen tent, 'At least he'll die with a good colour.'

The sugars gave the paediatricians of those days a worrisome time. The cult of similarity taught that the only sugar suitable for infant feeding was lactose, and this despite its expense was the sugar commonly used. Sugar of some kind must have been used as an addition to milk from time immemorial. In Isaiah VII verses 14 and 15 we read: 'A young wife shall become pregnant and give birth to a son named Immanuel. He shall be fed on rich milk and honey.' Yet in the intestinal derangements of infants sugar was the villaineven lactose. Fermentative diarrhoeas were rife, and all of these, diagnosed by inspection of the stools, were 'obviously' caused by the fermentation of the sugar. Therefore non-fermentable sugars were recommended and preparations containing various proportions of dextrins and maltose came into use. Polycarbohydrate feedings became a short vogue - a little lactose, malt sugar, sucrose and some starch, to dilute, as one author of the time put it, the injurious effect of each. Oscar Schloss dared to increase the carbohydrate content of feeding mixtures up to $20 \%$ in order to show that the sugar was not a factor in the causation of so-called fermentative diarrhoeas. 
It was John Howland who put the quietus on any sugar controversy. During the first World War the price of lactose rose to $\$ 1.25$ per pound and thus became prohibitive for people of modest means. He dared to use sucrose as the only carbohydrate and it rapidly became evident that no other sugar was required.

The cult of the acids forms an interesting chapter in the development of rational ideas of infant feeding. Despite all our theories with reference to the dilution of cow's milk, it has been known for centuries that milk fermented with lactic acid bacilli could be well tolerated undiluted. In the scientific era this was taught to be due not to the acidity of the milk but to the effect of the bacilli, Metchnikoff was the great exponent of this theory. Did he not teach that by drinking fermented milk one could live to be a hundred. Metchnikoff while drinking this milk died at 71. Yet the idea persisted that there was some benefit from the bacilli themselves until Marriott wondered if it were not the acid rather than the bacilli that made soured milk more easily tolerated. He showed very simply that the buffers in cow's milk were such that it required three times as much decinormal hydrochloric acid to bring it down to a $p \mathrm{H}$ of 6 than it did when breast milk was used for the experiment. He reasoned therefore that the gastric hydrochloric acid of the infant was used up by the cow's milk and was therefore unavailable for peptic digestion. This is probably still true for the sick infant and one might at times be well advised in some cases still to use acidified milk, but it hardly applies for the well infant. There followed at this time a veritable epidemic of papers on acidifying milk. Each new acid produced a new paper: Alfred Hess with lemon juice, several others with citric acid, vinegar, nitro-hydrochloric and hydrochloric acid. This last deserves some mention.

One of the contributors to the question of acidified milk was Harold K. Faber. He found that by the addition of $25 \%$ decinormal hydrochloric acid to sweet milk, the $p \mathrm{H}$ could be lowered to 6 without appreciably altering the taste. This was published in 1923. It was about at this time that the important work of Gamble, Ross and Tisdall appeared on the effect of acid-producing substances in the control of infantile tetany. They showed, in effect, that it was not the calcium in calcium chloride that controlled infantile tetany but rather that it was the chlorine ion; that ammonium chloride would do as well. Long before this, Emmett Holt had taught that calcium lactate had no effect on tetany, but that calcium chloride had. This was the empirical observation of a great clinician. What Faber did with his hydrochloric acid milk, for me at any rate, was to teach me a very simple and most effective way of treating tetany. Hydrochloric acid milk never became a vogue and now is probably never used; yet in the spring of the year, when the paediatrician's fancy lightly turns to thoughts of tetany, my thoughts turn to hydrochloric acid milk. It requires only the addition of $25 \mathrm{ml}$. of decinormal hydrochloric to each $100 \mathrm{ml}$. of cold milk, sweetened in the usual way, to control the infantile tetany which we still see in Canada in the spring of each year. Thus Faber's paper was not written in vain.

The combined ideas of the harmfulness of sugar and of the benefits of acid milk had led Finkelstein some years before to invent Eiweiss milch, later called albumin milk, and finally protein milk. Through many complicated contortions a milk was produced that was high in fat, high in calcium caseinate, low in lactalbumin and low in sugar. The idea was first that by reducing the quantity of sugar, the fermentation in the intestine was reduced and by increasing the relative proportions of fat and calcium caseinate, the insoluble soaps in the stool were greatly increased, thus leading to a stool of firmer consistency. This is quite true-for the well baby or for the baby with a short-lived or self-limited diarrhoea-but for the sick infant with rapid peristalsis it is a different story. The vogue of protein milk has far from died out and the exact teachings of our paediatric forebears have been replaced by a vagueness as to its origin and its purpose. Our newer concepts of the relation of parenteral infections to diarrhoeas, the use of antibiotics, the search for and elimination of sources and, above all, the use of intravenous solutions for the maintenance of fluid and mineral balance should long ago have relegated protein milk to the limbo of forgotten things. Protein milk, when it was effective, was a cork; it paid more attention to the character of the intestinal contents than to the biochemical and the fluid equilibrium of the infant.

For reasons which are difficult for us now to understand heated controversies raged on both sides of the Atlantic over the question of boiling milk for infant feeding. Apparently boiling of milk was harmful. Vitamins were destroyed, enzymes were destroyed. The fact that bacteria were destroyed and that vitamins (only vitamin $\mathrm{C}$ was affected) could be provided in greater abundance from other sources did not seem to bear much weight with the zealots. The enzymes were said to be very important, but just how or why and whether replaceable or not were questions to which straightforward answers were not to be had. The Walker Gordon Milk Laboratories were established in 1891. 
Their purposes were first to produce certified milk. This was a raw, unpasteurized milk produced with the greatest possible cleanliness from tuberculintested herds. Bacterial counts as low as 2,000 per cubic centimetre were not uncommon. The other purpose was to establish laboratories for preparing the baby's formula. Certified milk sold at that time at 25 cents the quart when milk of lesser quality sold at from six to nine cents the quart. The day labourer earned a dollar a day and the office clerk from 12 to 20 dollars a week. It was obvious that certified milk was not for the masses and that no problems were solved by this luxury. The apogee of this luxury was the formula department. At a cost of about one dollar a day the milk laboratory would prepare the infant's formula according to the doctor's prescription, divide it into sterilized feeding bottles and deliver it daily in a miniature refrigerator to the fortunate household. The poor darling of the rich, the mother, was thus spared the trials of preparing her infant's intricate formula, of giving an hour of her precious time to such menial tasks and was saved from the danger of adding an ounce too much milk or an unlevel tablespoonful of sugar. The prescription was a doctor's prescription, complete with the reputed sign of Jupiter. It was, of course, far too simple to order so many ounces of milk, so many of water and so much sugar or lactose. One wrote on this prescription something like this: Fat $2.75 \%$, carbohydrate (lactose) $6.5 \%$, protein $1.8 \%$, six feedings, $5 \mathrm{oz}$. each-let the technician figure it out, no doubt with a slide rule.

The problem of vomiting or the passing of tough casein curds had to be solved. Raw whole milk entering the infant's stomach is converted into a solid mass of casein; the late Joseph Brenneman called milk 'one of the most peculiarly and uniquely solid foods that is ever used'. These huge curds which could be vomited and which could cause death by aspiration could also pass through the intestine scarcely touched by proteolytic enzymes or bacteria. Since milk must not be boiled, some means must be found to reduce curd tension. The cereal diluent was ideal for this purpose. Hence barley water and oatmeal gruel; the colloidal action of these substances permitted the formation of soft, flocculent curds. Soured milk, acidified milk, boiled milk, gelatin were all effective and had their advocates, but at last the scientists demonstrated that passing ultrasonic waves through milk produced a flocculent curd and thus the problem was for ever solved. But this solution came at a time when there was no further need for it, for the boiling of milk for infant feeding had by now become almost universal.

Since certified milk solved no problem on any large scale, it was left to Howland to use what was called grade ' $B$ ' milk boiled for sterilization, with about $5 \%$ of cane sugar added. Vitamin $C$ had long since been added to the diet of all artificially fed infants and now it only remained for Howland, Hess, Chick and many others to clarify the real purpose and the need of cod liver oil as a regular supplement to the infant's diet. The conquest of rickets was well on the way, infants began to thrive and paediatricians became physicians for the young of the race instead of highly paid nannies.

The prejudice against evaporated and dried milks, very strong at one time, was quickly overcome by Marriott and through him the use of corn syrup became very popular. We physicians are ever addicted to playing the great game of follow the leader.

Out of this simplification of infant feeding there evolved three simple principles, whatever the method. They are adequacy, sterility and accessory factors. The provision of an amount of whole milk sufficient to meet the fat and protein requirements of the infant, and the addition of sufficient sugar, any sugar, to supplement the caloric deficiency of the milk allowance with sufficient water to meet the fluid needs of the infant and the provision of adequate vitamin supplements. It is interesting to observe that in other days milk was diluted because it was 'too strong' for the baby; now, however, water is added only in order to supply a need for fluids. We are still doing the same thing, but the reason is different. The boiling of the milk mixture not only insures its sterility but solves the curd problem as well while the addition of vitamins $C$ and $D$ have made rickets and scurvy a mere memory.

So has what loomed as an esoteric subject a mere 30 years ago has turned out to be what it always should have been-simple and obvious.

The late John Rurah sketched the whole history of infant feeding humorously in a short poem which ends as follows:

A hundred years will soon go by

Our places will be filled

By others who will theorize

And talk as long and look as wise

Until they too are stilled.

And I predict no one will know

What makes the baby gain and grow. 